\title{
ADHD Symptomatology and Its Relationship to Factors Associated With College Adjustment
}

Kate Norwalk

Jill M. Norvilitis

Michael G. MacLean

State University of New York College at Buffalo

\begin{abstract}
Objective: The present study assessed the relationship between self-reported ADHD symptomatology in college students and various factors that are associated with persistence in college. Method: A total of 321 students completed questionnaires examining ADHD symptoms, academic and social adjustment to college, career decision-making self-efficacy, study skills, and GPA. Results: Analyses indicated that higher levels of ADHD symptoms were significantly related to lower levels of career decision-making self-efficacy, academic adjustment, study skills, and GPA. Regression analyses revealed that only the inattentive cluster of symptoms was a significant predictor of career decision-making self-efficacy, study skills, and academic adjustment. Conclusion: These results suggest that the inattentive symptoms of ADHD may have a particularly negative effect on success in college. (J. of Att. Dis. 2008; $x x(x) \times x x-x x x$ )
\end{abstract}

Keywords: ADHD; inattention; college; adjustment

A lthough ADHD was once believed to affect only children, recent research has indicated that the symptoms of ADHD persist past childhood and adolescence well into college age and beyond. This can cause a variety of problems in numerous domains, including school, work, and home. Those with ADHD who attend college may have a more difficult time dealing with the academic, social, and career-planning demands. This may lead to lower rates of college success and higher rates of dropping out. This study looks at how ADHD symptoms are related to different facets of college adjustment and competence among young adults.

\section{ADHD Symptoms in Adolescence and Adulthood}

Although there is a wealth of research available on childhood ADHD, less is known about its carryover into adulthood, particularly among those of college age. It is estimated that one half to two thirds of children who are diagnosed with ADHD continue to show symptoms into adolescence and adulthood (Resnick, 2005), although persistence rates vary by the definition of ADHD that is used. In their evaluation of 19-year-old boys diagnosed with ADHD in childhood, Biederman, Mick, and Faraone (2000) reported that although 60\% no longer met full diagnostic criteria, $90 \%$ continued to struggle with significant, but subthreshold, levels of ADHD symptoms. Furthermore, they noted that symptoms of inattention were less likely to decline than were symptoms of hyperactivity and impulsivity.

The actual number of college students with ADHD is unknown, and much of the research on the prevalence of ADHD among college students relies on students' self reports of symptoms. For example, Weyandt, Linterman, and Rice (1995) administered the Adult Rating Scale, a self-report scale used to measure the level of ADHD symptoms in adults, and also the Wender Utah Rating Scale, a retrospective survey of childhood ADHD, to a sample of 770 college students. They found that $7 \%$ reported significant symptoms on the Adult Rating Scale, $8.7 \%$ reported significant symptoms on the Wender Utah Rating Scale, and 2.5\% reported symptoms

Authors' Note: This study was supported by a Buffalo State College Student Mini-Grant awarded to Kate Norwalk. Address correspondence to Jill M. Norvilitis, Department of Psychology, State University of New York College at Buffalo, 1300 Elmwood Avenue, Buffalo, NY 14222; norviljm@buffalostate.edu. 
on both scales (Weyandt et al., 1995). Similarly, in a cross-cultural study DuPaul et al. (2001) administered the Young Adult Rating Scale to 1,209 college students from universities in the United States, Italy, and New Zealand and found that prevalence rates of self-reported symptoms that met diagnostic criteria in the Diagnostic and Statistical Manual of Mental Disorders (4th ed., or DSM-IV; American Psychiatric Association, 1994) ranged from $0 \%$ to $8.1 \%$. Collectively, studies of this nature have revealed that approximately $2 \%-8 \%$ of college students report significant symptoms of ADHD, although the exact prevalence of those with a full diagnosis is unknown (Weyandt \& DuPaul, 2006).

Part of what makes determining the prevalence of ADHD in college students difficult is that the DSM-IV criteria for ADHD were designed to describe childhood symptoms, and growing evidence suggests they may not adequately capture the disorder as it occurs in late adolescence and adulthood. For example, adolescents and adults may not meet the minimum criteria listed in the $D S M-I V$, yet their functioning may still be impaired by their ADHD symptomatology (Ingram, Hechtman, \& Morgenstern, 1999). ADHD symptoms in adolescents and adults also appear to be somewhat different from those in childhood. Symptoms such as hyperactivity often decline, whereas symptoms of inattention remain constant. Impulsivity turns into deficits in executive functions, which include planning, delay of gratification, self-control, and dividing and focusing attention (Wasserstein, 2005). Consequences of these deficits typically include putting off important tasks in both school and work, forgetfulness, and being disorganized (Resnick, 2005). Another common symptom is mental restlessness. Weyandt et al. (2003) administered an Internal Restlessness Scale to 20 college students who had ADHD and 20 who did not. They found that those diagnosed with ADHD showed significantly higher scores of internal restlessness than those who were not. They also found the ADHD sample scored significantly higher on all four dimensions of restlessness: internal distractibility, internal restlessness, internal impulsivity, and internal disorganization (Weyandt et al., 2003).

\section{ADHD and College Performance}

Studies looking at college students with symptoms of ADHD have identified higher rates of a variety of academic problems, including lower GPAs, increased rates of academic probation (Heiligenstein, Guenther, Levy, Savino, \& Fulwiler, 1999), poorer time-management skills, and deficient test strategies (Reaser, Prevatt, Petscher, \& Proctor, 2007). Impulsivity, a common symptom of
ADHD, has also been shown to negatively affect academic performance in college. Specifically, high ratings of impulsivity have been strongly correlated with lower grades in college (Spinella \& Miley, 2003), perhaps because impulsivity can interfere with studying and the self-regulation to complete tasks. The types of attention deficits common in students with ADHD involve sustained, executive, and selective attention and can be manifested through problems in filtering out irrelevant from relevant information and ignoring what is not relevant, paying attention for extended periods of time without interrupting, and drawing attention away from one task to focus on a new one (Tsal, Shalev, \& Mevorach, 2005). These are all tasks that may be closely related to college success.

In addition to academic difficulties, college students with ADHD seem to have a more difficult time adjusting to college socially and emotionally. One study compared 20 college students who had been diagnosed with ADHD with a non-ADHD control group that was matched on age and gender (Shaw-Zirt, Popali-Lehane, \& Chaplin, 2005). The ADHD group scored significantly lower on scales measuring academic adjustment to college and on social adjustment, personal-emotional adjustment, attachment to college, and goal commitment. The ADHD group also scored significantly lower on measures of self-esteem and overall social skills.

A final indicator of college adjustment is career decisionmaking self-efficacy (CDMSE). This is the belief in one's own abilities to effectively make decisions about, and plan for, careers and education (Betz \& Taylor, 2001). Peterson and Delmas (2002) found that CDMSE had a significant effect on a student's academic integration, which in turn was a significant predictor of persistence in college. Academic integration is the extent to which the needs, interests, and preferences of a student match up with those of the university or college that he or she is attending. This is facilitated through interactions with faculty and the overall academic experience itself (Peterson \& Delmas, 2002). Although this has yet to be examined in those with ADHD symptoms, given the skills required, it is possible that higher levels of ADHD symptoms are also related to difficulties in this area.

\section{Considering the Effects of Different Types of ADHD Symptoms}

Currently, little is known about the relative contribution of inattention symptoms and hyperactivity/impulsivity symptoms to academic and social adjustment problems in college. However, research in children has suggested that deficits in cognitive and academic functioning may 
be particularly problematic in the primarily inattentive subtype as opposed to the hyperactive subtype. For example, in a study of children, Todd et al. (2002) reported that the primarily inattentive and combined subtype groups scored significantly lower on the cognitive and achievement tests, and their parents also reported worse grades and more placement in special education than their primarily hyperactive counterparts. Studies of those with the primarily inattentive subtype have shown greater deficits in executive functions as well. One such study measured 105 adults with ADHD and 90 controls for processing speed and executive functions via a neuropsychological battery. Results showed that the persistent inattentive group scored significantly lower than the persistent hyperactive group on measures of executive functions. Inattention was also associated with slower processing speed, and hyperactivity was associated with faster processing speed (Nigg et al., 2005). In a study that considered childhood inattention and hyperactivity/ impulsivity symptoms as separate predictors, the inattention symptoms were found to be predictive of substance use among adolescents with ADHD (Molina \& Pelham, 2003). These studies suggest that it is useful to consider the inattention and impulsivity/hyperactivity symptom dimensions separately when assessing the effects of ADHD on various outcomes.

It is clear that college students with symptoms of ADHD face difficulties in their academic careers, although the relative importance of inattentive and hyperactive/impulsive symptoms is less well understood. In the present study, we sought to explore these difficulties in college adjustment and examine their relationship to inattentive and hyperactive symptom clusters. The specific hypotheses of this study are as follows:

1. The first hypothesis is a partial replication of a previous study examining academic and social adjustment among college students with ADHD (Shaw-Zirt et al., 2005). We hypothesize that higher levels of ADHD symptoms will be related to lower levels of academic and social adjustment, factors that have been shown to contribute to higher college drop-out rates. Academic adjustment includes being able to adapt to the new academic demands of college, whereas social adjustment refers to the student's ability to have successful interpersonal relationships, including making friends and joining groups.

2. College students with higher levels of ADHD symptoms will have lower levels of CDMSE.

3. College students with higher levels of ADHD symptoms will have lower levels of academic performance, evident through poor study habits and skills and lower GPAs.

4. Furthermore, we expect that symptoms of inattention will be more predictive of academic and social difficulties than will symptoms of hyperactivity.

\section{Method}

\section{Participants}

The sample consisted of 321 students. Participants were recruited from introductory and upper level undergraduate psychology courses and were given extra credit or a candy bar for participating. Ages ranged from 18 to $49(M=$ $20.04, S D=4.33$ ). Because of concerns that nontraditional students might represent a different population, the 33 participants older than age 24 were excluded from subsequent analyses. In addition, another 21 students were omitted because of scores exceeding the cutoff on the Conners' Adult ADHD Rating Scale (CAARS) inconsistency index, which aims to identify strange or irregular responses (Conners, Erhardt, \& Epstein, 1999). An additional 4 participants who did not complete the CAARS were also excluded. This yielded a final sample of 263 participants.

There were 71 male and 192 female participants in the sample. Of these, 107 were freshmen, 28 were sophomores, 46 were juniors, and 72 were seniors. Three students were graduate level, and 7 participants did not specify year in school. The sample consisted of 198 Caucasian, 41 African American, 8 Hispanic, 5 Asian, and 8 biracial participants. Three participants did not specify their ethnicity. Self-reported college GPA ranged from 1.31 to $4.0(M=3.06, S D=0.54)$, and high school GPA ranged from 2.0 to $4.0(M=3.35, S D=0.41)$.

\section{Materials}

ADHD symptomatology. To assess the level of ADHD symptoms, a brief version of the CAARS was used (Conners et al., 1999). The scale was originally developed to aid in diagnosis of ADHD for individuals age 18 and older. The brief version consists of 26 items derived from the longer version, which has 66 . The CAARS is composed of four factors: Inattention/Memory Problems, Hyperactivity/Restlessness, Impulsivity/Emotional Liability, and Problems With Self-Concept. Although less work has been done with the short form, the original CAARS has been shown to be effective in correctly diagnosing $85 \%$ of ADHD cases in adults (Erhardt, Epstein, Conners, Parker, \& Sitarenios, 1999). Furthermore, Conners et al. (1999) reported that observer reports of behavior were moderately to highly correlated with the CAARS-Short 
Form. The CAARS also includes an ADHD Index, designed to identify adults who are likely to be diagnosed with ADHD, and an Inconsistency Index. In the present study, internal consistency was acceptable, as the ADHD Index yielded a coefficient alpha of .75, the Inattention Scale an alpha of .71, and the Hyperactivity Scale an alpha of .68.

Following the CAARS items, participants were asked to indicate whether they had ever been formally diagnosed with ADHD. Responses included "Yes, and I currently take medication for it," "Yes, and I do not currently take medication for it," or "No." This item was placed last in the series of questions so as not to give away the nature of the study.

Nine of the final group of participants reported having been diagnosed with ADHD in the past. The $t$ scores on the ADHD Index of the CAARS ranged from 34 to 77 $(M=51.08, S D=8.37)$. Of the participants who reported ever receiving a formal diagnosis, only 2 obtained a $t$ score of 65 or higher, which is the suggested cutoff for a diagnosis of ADHD. An additional 1 of the previously diagnosed students scored above $60(M=55.78, S D=12.08)$.

Academic and social adjustment. To test the first hypothesis, that students showing symptoms of ADHD will have lower academic and social adjustment to school, the Academic Adjustment and Social Adjustment subscales of the Student Adaptation to College Questionnaire were used (Baker \& Siryk, 1984, 1989). The Student Adaptation to College Questionnaire is a self-report scale that is designed to measure how well a student is adjusting to college, with higher scores indicating higher levels of self-reported adjustment. Several studies have shown the Student Adaptation to College Questionnaire to have good content and predictive validity (Asher, 1992). In the current sample, the coefficient alpha was .85 for the Academic Adjustment subscale and .82 for the Social Adjustment subscale.

Career decision making. To test the second hypothesis, that college students showing symptoms of ADHD will have lower self-efficacy when it comes to making decisions about careers, a shortened version of the widely used CDMSE Scale was used (Betz, Klein, \& Taylor, 1996). This scale is designed to assess a student's beliefs in his or her abilities to make career decisions. It combines the selfefficacy theory of Bandura (1977), which states that selfefficacy, or the belief in one's own abilities, is an important factor in predicting behavior, with the career maturity theory of Crites (1978). This theory states that a person will make good career choices when he or she has positive beliefs in his or her own abilities (high self-efficacy) in five different domains of career choice. These domains are what make up the subscales of the CDMSE Scale, and they include self-appraisal, obtaining information about career options, goal selection, making plans for the future, and problem solving. The short version of the CDMSE Scale consists of 25 items, with responses ranging from 0 (no confidence at all) to 9 (complete confidence). Several validity studies have also shown good levels of content validity, as well as convergent validity, with the CDMSE Scale correlating highly with other scales measuring a similar construct (Betz \& Taylor, 2001). Discriminant and construct validities have also been shown in a number of studies through significant negative correlations between high scores on the CDMSE Scale and high levels of career indecision (see Betz \& Taylor, 2001). In the present study, coefficient alpha was .92.

Study skills. To assess effective study skills, we constructed an 11-item scale, consisting of questions about habits and skills related to academic achievement (e.g., "I read the textbooks and other assigned readings for my classes" and "I watch TV or listen to music while I study"). Participants used a 4-point Likert-type scale ranging from 1 (not at all like me) to 4 (always or very much like me) to rate how closely each item applied to them. Six of the items were reversed scored so that a higher overall scale score denoted better study skills. Three of the original 14 items were dropped because of detrimental effects on internal reliability. The final 11item scale yielded a coefficient alpha of .77.

Academic performance. Students were also asked to give their college GPAs on a 4-point scale. If the participant was a first-semester freshman, he or she was asked to give a high school GPA instead. However, given the inconsistency in the manner in which high school GPAs were reported and the lack of stability of freshman college GPAs, only sophomores, juniors, and seniors were included in the analysis of GPAs.

Depression. A final measure used was a short form of the Center for Epidemiologic Studies-Depression scale (CES-D; Radloff, 1977). Research has shown high rates of comorbidity between depression and ADHD in adults (Murphy \& Barkley, 1996; Torgersen, Gjervan, \& Rasmussen, 2006), and so we used the CES-D as a means to control for depressive symptoms. The CES-D is a 10item self-report scale chosen for its brevity and its utility in assessing depression in the general population as opposed to just clinical samples. Each item consists of a symptom of depression. Participants are asked to rate each item on a 4-point Likert-type scale ranging from 1 (rarely, or none of the time) to 4 (all of the time) the frequency with which that symptom was experienced within the past week. Studies have shown strong reliability and 
Table 1

Summary of Regression Analysis Results

\begin{tabular}{|c|c|c|c|c|c|}
\hline Dependent Variable and Predictor Variables & $B$ & $S E B$ & $\beta$ & $p$ & Model $R^{2}$ \\
\hline Academic adjustment & & & & & $.29 *$ \\
\hline Depression & -1.92 & 0.29 & -.38 & $<.001$ & \\
\hline Gender & 8.90 & 3.34 & .15 & .01 & \\
\hline Hyperactivity & -0.24 & 0.19 & -.08 & .21 & \\
\hline Inattention & -0.77 & 0.20 & -.24 & $<.001$ & \\
\hline Social adjustment & & & & & $.15^{*}$ \\
\hline Depression & -1.75 & 0.28 & -.38 & $<.001$ & \\
\hline Gender & -1.15 & 3.27 & -.02 & .73 & \\
\hline Hyperactivity & 0.08 & 0.18 & .03 & .68 & \\
\hline Inattention & -0.12 & 0.19 & -.04 & .52 & \\
\hline Career decision-making self-efficacy & & & & & $.16^{*}$ \\
\hline Depression & -0.83 & 0.17 & -.31 & $<.001$ & \\
\hline Gender & 1.88 & 1.89 & .06 & .32 & \\
\hline Hyperactivity & 0.14 & 0.11 & .09 & .19 & \\
\hline Inattention & -0.33 & 0.11 & -.19 & .004 & \\
\hline Study skills & & & & & $.27 *$ \\
\hline Depression & -0.06 & 0.06 & -.06 & .30 & \\
\hline Gender & 2.90 & 0.70 & .23 & $<.001$ & \\
\hline Hyperactivity & -0.01 & 0.04 & -.02 & .79 & \\
\hline Inattention & -0.29 & 0.04 & -.45 & $<.001$ & \\
\hline GPA & & & & & .03 \\
\hline Depression & -0.01 & 0.01 & -.10 & .18 & \\
\hline Gender & 0.11 & 0.09 & .09 & .21 & \\
\hline Hyperactivity & 0.00 & 0.01 & .04 & .59 & \\
\hline Inattention & -0.01 & 0.01 & -.09 & .29 & \\
\hline
\end{tabular}

$* p<.001$.

validity for the CES-D (Cole, Rabin, \& Smith, 2004), with a coefficient alpha of .77 in the present study.

\section{Results}

Because of concerns about depression confounding results, we assessed the relationship between scores on the CES-D and the CAARS. A strong positive correlation was found between self-reported ADHD symptoms and scores on the CES-D $(r=.46, p<.001)$. This is not surprising, as high rates of comorbidity have been shown to exist between ADHD and depression, and there is overlap in some of the symptomatology (e.g., difficulty concentrating). Therefore, we performed further analyses controlling for depression.

We ran partial correlation analyses to examine the overall relationships between the ADHD Index of the CAARS and all variables of interest. Significant negative correlations were found between scores on the ADHD Index and academic adjustment $(r=-.32, p<.001)$, social adjustment $(r=-.15, p<.05)$, study skills $(r=$ $-.25, p<.001)$, and CDMSE $(r=-.27 p<.001)$. The relationship with GPA was not significant $(r=-.10, p=.25)$. To examine how much controlling for depression influenced the correlation estimates, we also calculated straight bivariate correlations between the ADHD Index and the variables of interest. In most cases, the magnitude of the relationship was similar to that of the partial correlation. However, it is worth noting that the correlation between social adjustment and ADHD symptoms rose to $-.25(p<.001)$, supporting the importance of controlling for depressive symptoms.

With the general relationship established, we completed a series of regression analyses to assess the relative importance of inattention and hyperactivity in predicting difficulties in college. In each regression model, scores on the CES-D and gender were entered in the first step as control variables. Initially, age was considered as a control variable. However, in assessing zero-order correlations, age was unrelated to any of the variables of interest. In the second step, scores from the Inattention and Hyperactivity subscales of the CAARS were added as the predictor variables. We considered evidence of multicollinearity because of the moderate correlations among the predictor variables. None of the predictors had a variance inflation factor exceeding 1.27, suggesting that multicollinearity had a minimal effect on parameter estimates. All regression model results are reported in Table 1.

All of the models, with the exception of the model predicting GPA, were significant, with the variance accounted 
for ranging from .15 to .29 . Of the control variables, depression significantly predicted academic adjustment, social adjustment, and CDMSE. Gender significantly predicted academic adjustment and study skills. Of the ADHD symptoms, it is noteworthy that inattention was a significant predictor of academic adjustment, CDMSE, and study skills, but hyperactivity was not a significant predictor in any of the models.

\section{Discussion}

The present study examined ADHD symptomatology in college students and its relation to various factors that have been associated with college adjustment. Specifically, these factors included CDMSE, academic and social adjustment to college, study skills, and GPA. The study further expanded on prior research to include an examination of the influence of inattention and hyperactivity in a general, largely subthreshold student population.

In support of prior research, we found significant relationships between higher levels of ADHD symptoms and lower levels of study habits and skills and academic adjustment to college. These results are not surprising, given the past research on the academic problems often encountered by college students with ADHD. These include lack of organizational skills, problems with focusing and sustaining attention, deficits in executive functions (Weyandt \& DuPaul, 2006), and using ineffective academic coping strategies, including procrastination and poor organization (Turnock, Rosen, \& Kaminski, 1998). Contrary to prior research, ADHD symptomatology was not related to social adjustment or GPA. This may well be because this study examined ADHD symptoms in a general population, most of whom had never been diagnosed with the disorder.

Furthermore, as originally predicted, the results showed a significant negative relationship between ADHD symptoms and CDMSE. Given that CDMSE is the belief in one's abilities to effectively make decisions about, and plan for, careers and education (Betz \& Taylor, 2001), it may be the deficits in executive functioning associated with ADHD (Wasserstein, 2005; Weyandt \& DuPaul, 2006), which include planning, that underlie this relationship. These deficits may make it difficult for students with ADHD symptoms to plan for their education and career goals. In addition, the poorer academic adjustment associated with ADHD may also undermine confidence in achieving educational and career goals.

Perhaps the most noteworthy finding is that only the inattention symptoms, and not the hyperactive symptoms, were predictive of lower CDMSE, study skills, and academic adjustment. Little research to date has examined the unique effect these different types of ADHD symptoms may have on college performance. However, the present study joins a growing body of literature that indicates that inattention is more strongly related to academic success than is hyperactivity. For example, primarily inattentive students have been shown to process information more slowly, a problem that can be amplified as additional distracters are added to the learning environment (Nigg et al., 2005; Weiler, Bernstein, Bellinger, \& Waber, 2002). Furthermore, in a study of children, Todd et al. (2002) reported that the primarily inattentive and combined subtype groups scored significantly lower on achievement tests and were more likely to be placed in special education than their primarily hyperactive counterparts. Moreover, research has suggested that individuals with ADHD classified as primarily inattentive may be uniquely susceptible to deficits in executive functions. These include planning ahead for the future, self-control, and dividing and focusing attention (Wasserstein, 2005).

Colleges provide a much less structured academic environment than does high school. As such, there may be many more potential distractions in college than students with ADHD are accustomed to. If the presence of added distracters has a particularly deleterious effect on primarily inattentive students, then they may be at an increased risk for failing academically, although this did not appear to be the case in the present study. Given the nature of the college environment and the findings of the present study, it appears that symptoms of inattention may be uniquely important in their effect on academic performance among college students, even among those never diagnosed with the disorder and whose symptoms are below the threshold for diagnosis.

Also important when considering college adjustment is the role of depression. Although depression was not the focus of this study, the strong relationship between depression and ADHD symptoms and between depression and adjustment indicates that this is an important factor, both for control in future research and for the consideration of those working with college students who are not adjusting well.

Given the correlational nature of the present study, no causal conclusions can be made regarding ADHD symptoms and the variables in question. Another potential limitation of this study is the low number of participants reporting an actual diagnosis of ADHD. Only 9 participants reported having received an actual diagnosis of ADHD at some point in their lives. Furthermore, as has prior research, this study relied on self-reports of ADHD 
symptoms rather than formal assessment. However, the presence of adjustment difficulties among those with subthreshold symptoms of ADHD suggests that these problems are robust and important to consider even among those who may not carry a diagnosis. A final concern is that the present study did not assess or control for the presence of learning disabilities, which are frequently comorbid with ADHD (Adler, Barkley, Wilens, \& Ginsberg, 2006). Future research should examine whether learning disabilities could help explain the relationship between ADHD symptoms and college adjustment.

Despite the limitations of the current study, it is one of very few that addresses whether the different types of ADHD symptoms are uniquely related to adjustment outcomes in college students. The results suggest that inattentive symptoms may be more closely related to academic and career planning difficulties than are hyperactive symptoms. Because research has suggested that symptoms of inattention often replace hyperactive symptoms of ADHD in adulthood (Wasserstein, 2005), it is particularly important to realize the negative effects that these symptoms have on college students so that assistance can be provided both academically and in terms of career counseling.

The results of this study may also have implications for colleges as they strive to improve retention. High enrollments result in more money and funding for the college by way of both tuition and government grants. Some of the factors related to higher drop-out rates and/or taking longer than 4 years to obtain a bachelor's degree include poor academic skills, low GPA, trouble managing an increased course load, and low CDMSE (Gerardi, 1996). The results of the current study suggest that students with higher levels of ADHD symptomatology may possess deficiencies in study skills, academic adjustment, and lower levels of CDMSE, which may mean that they are at a greater risk for not persisting in college. Future research should examine the relationship between inattention and hyperactivity and college adjustment in a longitudinal manner to further explore this issue.

\section{References}

Adler, L. A., Barkley, R. A., Wilens, T. E., \& Ginsberg, D. L. (2006). Differential diagnosis of attention-deficit/hyperactivity disorder and comorbid conditions. Primary Psychiatry, 13(5), 1-14.

American Psychiatric Association. (1994). Diagnostic and statistical manual of mental disorders (4th ed.). Washington, DC: Author.

Asher, J. E. (1992). Review of the Student Adaptation to College Questionnaire. In J. J. Kramer \& J. C. Conoley (Eds.), Eleventh Mental Measurements Yearbook. Lincoln, NE: Buros Institute of Mental Measurements. Available at http://proxy.buffalostate .edu:2048/login?url=http://search.ebscohost.com/login.aspx?direct= true \&AuthType $=$ ip, cookie, custuid, uid \&custid $=$ s $8999869 \& \mathrm{db}=$ loh\&AN=11120821\&loginpage $=$ Login. asp \&site $=$ ehost-live

Bandura, A. (1977). Self-efficacy: Towards a unifying theory of behavioral change. Psychology Review, 84, 191-215.

Baker, R. W., \& Siryk, B. (1984). Measuring adjustment to college. Journal of Counseling Psychology, 31, 179-189.

Baker, R. W., \& Siryk, B. (1989). Student Adaptation to College Questionnaire (SACQ): Manual. Los Angeles: Western Psychological Services.

Betz, N. E., Klein, K., \& Taylor, K. (1996). Evaluation of a short form of the Career Decision-Making Self-Efficacy Scale. Journal of Career Assessment, 4, 47-57.

Betz, N. E., \& Taylor, K. (2001). Manual for the Career Decision Making Self-Efficacy Scale and the CDMSE-Short Form. Columbus: Ohio State University.

Biederman, J., Mick, E., \& Faraone, S. V. (2000). Age-dependent decline of symptoms of attention deficit hyperactivity disorder: Impact of remission definition and symptom type. American Journal of Psychiatry, 157, 816-818.

Cole, J. C., Rabin, A. S., \& Smith, T. L. (2004). Development and validation of a Rasch derived CES-D short form. Psychological Assessment, 16, 360-372.

Conners, C. K., Erhardt, D., \& Epstein, J. N. (1999). Self-ratings of ADHD symptoms in adults: I. Factor structure and normative data. Journal of Attention Disorders, 3, 141-151.

Crites, J. O. (1978). Career Maturity Inventory. Monterey, CA: CTB/ McGraw-Hill.

DuPaul, G. J., Schaughency, E. A., Weyandt, L. L., Tripp, G., Kesiner, J., Ota, K., et al. (2001). Self-report of ADHD symptoms in university students: Cross gender and cross-national prevalence. Journal of Learning Disabilities, 34, 370-379.

Erhardt, D., Epstein, J. N., Conners, C. K., Parker, J. D. A., \& Sitarenios, G. (1999). Self ratings of ADHD symptoms in adults: II. Reliability, validity, and diagnostic sensitivity. Journal of Attention Disorders, 3, 153-158.

Gerardi, S. (1996). Factors which influence community college graduation. New York: City University of New York, New York City Technical College. (ERIC Document Reproduction Service Number ED398945)

Heiligenstein, E., Guenther, G., Levy, A., Savino, F., \& Fulwiler, J. (1999). Psychological and academic functioning in college students with attention deficit hyperactivity disorder. Journal of American College Health, 47, 181-185.

Ingram, S., Hechtman, L., \& Morgenstern, G. (1999). Outcome issues in ADHD: Adolescent and adult long-term outcome. Mental Retardation and Developmental Disorders, 5, 243-250.

Molina, B. S. G., \& Pelham, W. E. (2003). Childhood predictors of adolescent substance use in a longitudinal study of children with ADHD. Journal of Abnormal Psychology, 112, 497-507.

Murphy, K., \& Barkley, R. A. (1996). Attention deficit hyperactivity disorder adults: Comorbidities and adaptive impairments. Comprehensive Psychiatry, 37, 393-401.

Nigg, J. T., Stavro, G., Ettenhoffer, M., Hambrick, D. Z., Miller, T., \& Henderson, J. M. (2005). Executive functions and ADHD in adults: Evidence for selective effects on ADHD specific domains. Journal of Abnormal Psychology, 4, 706-717

Peterson, S. L., \& Delmas, R. C. (2002). Effect of career decision making self-efficacy and degree utility on student persistence: A pathanalytic study. Journal of College Student Retention, 3, 285-299.

Reaser, A., Prevatt, F., Petscher, Y., \& Proctor, B. (2007). The learning and study strategies of college students with ADHD. Psychology in the Schools, 44, 627-638. 
Resnick, R. J. (2005). Attention deficit hyperactivity disorder in teens and adults: They don't all outgrow it. Journal of Clinical Psychology, 61, 529-533.

Shaw-Zirt, B., Popali-Lehane, L., \& Chaplin, W. (2005). Adjustment, social skills, and self esteem in college students with symptoms of ADHD. Journal of Attention Disorders, 8, 109-120.

Spinella, M., \& Miley, W. M. (2003). Impulsivity and academic achievement in college students. College Student Journal, 37, 545-549.

Todd, R. D., Sitdhiraksa, N., Reich, W., Ji, T. H., Joyner, C. A., Heath, A. C., et al. (2002). Discrimination of DSM-IV and latent class attention deficit/hyperactivity disorder subtypes by educational and cognitive performance in a population-based sample of child and adolescent twins. Journal of the American Academy of Child \& Adolescent Psychiatry, 41, 820-828.

Radloff, L. S. (1977). The CES-D Scale: A self-report depression scale for research in the general population. Applied Psychological Measurement, 1, 385-401.

Torgersen, T., Gjervan, B., \& Rasmussen, K. (2006). ADHD in adults: A study of clinical characteristics, impairment, and comorbidity. Nordic Journal of Psychiatry, 60, 38-43.

Tsal, Y., Shalev, L., \& Mevorach, C. (2005). The diversity of attention deficits in ADHD: The prevalence of four cognitive factors versus controls. Journal of Learning Disabilities, 38, 142-157.

Turnock, P., Rosen, L. A., \& Kaminski, P. L. (1998). Differences in academic coping strategies of college students who self-report high and low symptoms of attention deficit hyperactivity disorder. Journal of College Student Development, 39, 484-493.

Wasserstein, J. (2005). Diagnostic issues for adolescents and adults with ADHD. Journal of Clinical Psychology, 61, 535-547.

Weiler, M. D., Bernstein, J. H., Bellinger, D., \& Waber, D. P. (2002). Information processing deficits in children with attentiondeficit/hyperactivity disorder, inattentive type, and children with reading disability. Journal of Learning Disabilities, 35, 448-461. Weyandt, L. L., \& DuPaul, G. (2006). ADHD in college students. Journal of Attention Disorders, 10, 9-19.

Weyandt, L. L., Iwaszuk, W., Fulton, K., Ollerton, M., Beatty, N., Fouts, H., et al. (2003). The Internal Restlessness Scale: Performance of college students with and without ADHD. Journal of Learning Disabilities, 36, 382-389.

Weyandt, L. L., Linterman, I., \& Rice, J. A. (1995). Reported prevalence of attentional difficulties in a general sample of college students. Journal of Psychopathology and Behavioral Assessment, 17, 293304.

Kate Norwalk, BA, graduated in May 2007 from the Department of Psychology at Buffalo State College. She is currently enrolled in the doctoral program in school psychology at Pennsylvania State University.

Jill M. Norvilitis, $\mathrm{PhD}$, is an associate professor in the Department of Psychology at Buffalo State College. Her research program examines ADHD in college students in the United States and China. Her recent work includes publications in the Journal of Attention Disorders, Psychology in the Schools, and the Journal of Personality Assessment.

Michael G. MacLean, PhD, is an associate professor in the Department of Psychology at Buffalo State College. His research program focuses on the etiology and prevention of substance use-related problems in adolescents and young adults. His recent work includes publications in Addictive Behaviors and the Journal of Studies on Alcohol. 